\title{
PROMOSI KESEHATAN MENGGUNAKAN MEDIA LEAFLET TERHADAP KEBERSIHAN GIGI DAN MULUT SISWA KELAS VIII SMP
}

\author{
Jeana Lydia Maramis ${ }^{1}$, Novarita M. Koch ${ }^{2}$, Miftahul J. Paputungan ${ }^{3}$ \\ 1,2,3)Jurusan Keperawatan Gigi Poltekkes Kemenkes Manado \\ Email : jeanalydiamaramis@gmail.com
}

\begin{abstract}
ABSTRAK
Pendahuluan : Kebersihan gigi dan mulut adalah bersihnya rongga mulut, gigi dan lidah, serta bebasnya gigi dan mulut dari semua kotoran atau sisa-sisa makanan. Promosi kesehatan adalah suatu kegiatan atau usaha menyampaikan pesan kesehatan kepada masyarakat, kelompok, atau individu. Penelitian ini bertujuan untuk mengetahui efektivitas promosi kesehatan menggunakan media leaflet terhadap kebersihan gigi dan mulut siswa kelas VIII SMP Negeri 1 Sangkub Kabupaten Bolaang Mongondow Utara. Metode : Jenis penelitian yang digunakan dalam penelitian ini yaitu Quasi Eksperimental dengan rancangan One Group pretest posttest. Penelitian ini dilakukan pada bulan Mei 2019 dan berlokasi di SMP Negeri 1 Sangkub Kabupaten Bolaang Mongondow Utara. Cara pengambilan sampel yaitu total sampling, dengan jumlah sampel 50 responden. Instrumen penelitian menggunakan format pemeriksaan OHIS dan media leaflet. Data yang diperoleh kemudian ditabulasi dan untuk melihat efektivitas promosi kesehatan menggunakan media leaflet terhadap kebersihan gigi dan mulut dengan menggunakan uji Paired Sample t Test. Hasil : Hasil penelitian ini menunjukkan bahwa sebelum diberikan promosi kesehatan menggunakan media leaflet didapatkan kriteria OHIS yang paling banyak yaitu kriteria sedang dan sesudah diberi perlakuan kriteria OHIS menjadi baik. Berdasarkan hasil analisa statistik melalui uji Paired Sample $t$ Test pada tingkat kemaknaan $95 \%(\alpha=0.05)$ diperoleh nilai $p=0.000(p<0.05)$. Maka dapat disimpulkan bahwa promosi kesehatan dengan menggunakan media leaflet memiliki efektivitas terhadap kebersihan gigi dan mulut.
\end{abstract}

\section{Kata Kunci : Promosi kesehatan, Media Leaflet, OHIS}

\begin{abstract}
Introduction : Tooth and mouth hygiene is the cleanliness of the oral cavity, teeth and tongue, as well as free teeth and mouth from all impurities or food debris. Health promotion is an activity or effort to deliver health messages to the public, groups, or individuals. This study aims to determine the effectiveness of health promotion using leaflet media on dental and oral hygiene of Grade VIII students of SMP Negeri 1 Sangkub, North Bolaang Mongondow Regency. Methods : The type of research used in this study is Quasi Experimental with One Group pretest posttest design. This research was conducted in May 2019 and located in SMP Negeri 1 Sangkub North Bolaang Mongondow Regency. The sampling method is total sampling, with a total sample of 50 respondents. The research instrument used the OHIS examination format and leaflet media. The data obtained were then tabulated and to see the effectiveness of health promotion using leaflet media on dental and oral hygiene using the Paired Sample t Test. Result : The results of this study indicate that before being given health promotion using leaflet media, the most OHIS criteria were found, the moderate criteria and after being treated OHIS criteria became good. Based on the results of statistical analysis through the Paired Sample t Test at a significance level of $95 \%(\alpha=$
\end{abstract}


$0.05)$, the value of $\mathrm{p}=0.000(\mathrm{p}<0.05)$ was obtained. So it can be concluded that health promotion using leaflet media has effectiveness on dental and oral hygiene

\section{Keywords : Health Promotion, Leaflet, OHI-S}

\section{PENDAHULUAN}

Kesehatan gigi dan mulut penting bagi kehidupan, karena mulut bukan sekedar pintu masuk untuk makanan dan minuman, tetapi mempunyai peranan penting dalam pencernaan makanan, estetik dan komunikasi. Mulut adalah "cermin dari kesehatan gigi" karena secara umum banyak gejala-gejala penyakit yang dapat dilihat di dalam mulut. ${ }^{1}$ Selain itu, kesehatan mulut penting bagi kesehatan dan kesejahteraan tubuh secara umum dan sangat mempengaruhi kualitas kehidupan, termasuk fungsi bicara, pengunyahan, dan rasa percaya diri. ${ }^{2}$ Kebersihan gigi dan mulut adalah bersihnya rongga mulut, gigi dan lidah, serta bebasnya gigi dan mulut dari semua kotoran atau sisa-sisa makanan. $^{3}$

untuk $\begin{gathered}\text { Promosi kesehatan adalah upaya } \\ \text { meningkatkan kemampuan }\end{gathered}$ masyarakat melalui pembelajaran dari, oleh, untuk dan bersama masyarakat, agar mereka dapat menolong diri sendiri, serta mengembangkan kegiatan yang bersumber daya masyarakat, sesuai sosial budaya setempat dan didukung kebijakan publik yang berwawasan kesehatan. ${ }^{4}$ Secara definisi istilah promosi kesehatan dalam ilmu kesehatan masyarakat (health promotion) mempunyai dua pengertian. Pengertian pertama adalah sebagai bagian dari tingkat pencegahan penyakit. Level and Clark, mengatakan adanya empat tingkatan pencegahan penyakit dalam perspektif kesehatan masyarakat, yaitu: a. Health promotion (peningkatan/ promosi kesehatan).

b. Specifik protection (perlindungan khusus melalui imunisasi).

c. Early diagnosis and prompt treatment (diagnosis dini dan pengobatan segera).

d. Disability limitation (membatai atau mengurangi terjadinya kecatatan).

e. Rehabilitation (pemulihan).

Tujuan promosi kesehatan menurut WHO :

a. Mengubah perilaku individu atau masyarakat dibidang kesehatan

b. Menjadikan kesehatan sebagai sesuatu yang bernilai bagi masyarakat

c. Menolong individu agar mampu secara mandiri atau berkelompok mengadakan kegiatan untuk mencapai tujuan hidup sehat

d. Mendorong pengembangan dan penggunaan secara tepat sarana pelayanan kesehatan yang ada.

Media berasal dari bahasa latin dan merupakan bentuk jamak dari kata medium yang secara harfiah berarti perantara atau pengantar. ${ }^{5}$ Menurut Heinich, (1993) cit. Susilana dan Riyana (2007) media merupakan alat saluran komunikasi. Heinich mencontohkan media ini seperti film, televisi, diagram, bahan cetak, komputer dan instruktur. Contoh media tersebut bisa dipertimbangkan sebagai media pembelajaran jika membawa pesan (messages) dalam rangka mencapai tujuan pembelajaran. $^{6}$ 
Media promosi kesehatan adalah semua sarana atau upaya untuk menampilkan pesan atau informasi yang ingin disampaikan oleh komunikator, baik itu melalui media cetak, elektronika, (TV, Radio, Komputer, dan sebagainya) dan media luar ruang, sehingga sasaran dapat meningkat pengetahuannya yang akhirnya diharapkan dapat berubah perilakunya ke arah positif terhadap kesehatan. ${ }^{7}$

Tujuan atau alasan mengapa media sangat diperlukan didalam pelaksanaan promosi kesehatan antara lain:

a. Media dapat mempermudah penyampaian informasi

b. Media dapat menghindari kesalahan persepsi

c. Dapat memperjelas informasi

d. Media dapat mempermudah pengertian

e. Mengurangi komunikasi yang verbalistik

f. Dapat menampilkan objek yang tidak bisa di tangkap dengan mata

Menurut Suiraoka \& Suparisa (2012) Leaflet adalah selembar kertas yang dilipat-lipat, berisi tulisan cetak dan beberapa gambar tertentu tentang suatu topik khusus untuk sasaran dan tujuan tertentu. Ukuran umumnya $20 \times 30 \mathrm{~cm}$, dengan jumlah tulisan umumnya 200-400 kata, secara umum berisi garis-garis besar penyuluhan dan isi harus dapat ditangkap dengan sekali baca. leaflet biasanya diberikan setelah pelajaran atau penyuluhan selesai dilaksanakan atau dapat pula diberikan sewaktu penyuluhan berlangsung untuk memperkuat ide yang disampaikan. ${ }^{5}$

Kebersihan gigi dan mulut adalah bebasnya gigi dan mulut dari sisa makanan dan kuman-kuman yang merusak gigi.
Deposit atau lapisan yang menumpuk pada permukaan gigi dapat dikelompokkan menjadi acquired pellicle, material alba, debris makanan, plak gigi, dental stain dan kalkulus. $^{2}$

Mengukur kebersihan gigi dan mulut merupakan upaya untuk menentukan keadaan kebersihan gigi dan mulut seseorang. Pada umumnya untuk mengukur kebersihan gigi dan mulut digunakan suatu indeks. Indeks adalah suatu angka yang menunjukkan keadaan klinis yang didapat pada waktu dilakukan pemeriksaan, dengan cara mengukur luas dari permukaan gigi yang ditutupi oleh plak maupun kalkulus, dengan demikian angka yang diperoleh berdasarkan penilaian yang objektif. Mengukur kebersihan gigi dan mulut, Green and Vermilion menggunakan indek yang dikenal dengan Oral Hygiene Index Simplified (OHI-S). Untuk mengukur kebersihan gigi dan mulut seseorang, Green and Vermillion memilih enam permukaan gigi indeks tertentu yang cukup dapat mewakili segmen depan maupun belakang dari seluruh pemeriksaan gigi yang ada dalam rongga mulut. Gigi-gigi yang dipilih sebagai gigi indeks beserta permukaan indeks yang dianggap mewakili tiap segmen adalah:

a. Gigi 16 pada permukaan bukal

b. Gigi 11 pada permukaan labial

c. Gigi 26 pada permukaan bukal

d. Gigi 36 pada permukaan lingual

e. Gigi 31 pada permukaan labial

f. Gigi 46 pada permukaan lingual

Skor OHIS diperoleh dengan cara menjumlahkan skor debris indeks dan kalkulus indeks: OHIS = Debris Indeks + Kalkulus Indeks. OHIS mempunyai kriteria tersendiri, yaitu mengikuti ketentuan sebagai berikut: 
a. Baik (good, jika nilainya antara 0,0-1,2

b. Sedang (fair), jika nilainya antara 1,33,0

c. Buruk (poor), jika nilainya antara 3,1$6,0 .^{2}$

\section{METODE}

Jenis penelitian yang akan digunakan dalam penelitian ini yaitu penelitian Quasi Eksperimental dengan rancangan "One Group Pretest Posttest”. Teknik sampel yang digunakan dalam penelitian ini yaitu total populasi (total sampling) yang berjumlah 48 siswa kelas VIII SMP Negeri 1 Sangkub Kabupaten Bolaang Mongondow Utara. Pelaksanaan penelitian dilakukan pada bulan Mei minggu ke empat tahun 2019. Analisa data dalam penelitian ini menggunakan uji statistik Paired Sample t Test.

\section{HASIL}

1. Distribusi responden berdasarkan jenis kelamin siswa kelas VIII SMP Negeri 1 Sangkub Kabupaten Bolaang Mongondow Utara dapat dilihat pada Tabel 1 di bawah ini:

Tabel 1. Distribusi Responden Berdasarkan Jenis Kelamin

\begin{tabular}{ccc}
\hline $\begin{array}{c}\text { Jenis } \\
\text { Kelamin }\end{array}$ & $\begin{array}{c}\text { Jumlah } \\
\text { Siswa }\end{array}$ & $\begin{array}{c}\text { Persentase } \\
(\%)\end{array}$ \\
\hline Laki-laki & 24 & 50 \\
Perempuan & 24 & 50 \\
\hline Total & 48 & 100 \\
\hline
\end{tabular}

Pada Tabel 1 di atas menunjukkan bahwa antara responden perempuan dan laki-laki memiliki jumlah yang sama yaitu 24 responden $(50 \%)$.

2. Distribusi responden berdasarkan golongan umur siswa kelas VIII SMP
Negeri 1 Sangkub Kabupaten Bolaang Mongondow Utara dapat dilihat pada Tabel 2 berikut ini:

Tabel 2. Distribusi Responden Berdasarkan Golongan Umur

\begin{tabular}{ccc}
\hline $\begin{array}{c}\text { Umur } \\
\text { (Tahun) }\end{array}$ & $\begin{array}{c}\text { Jumlah } \\
\text { Siswa }\end{array}$ & $\begin{array}{c}\text { Persentase } \\
(\%)\end{array}$ \\
\hline 13 & 16 & 33,3 \\
14 & 25 & 52,1 \\
15 & 7 & 14,6 \\
\hline Total & 48 & 100 \\
\hline
\end{tabular}

Data pada Tabel 2, menunjukkan bahwa jumlah responden yang paling banyak terdapat pada umur 14 tahun $(52,1 \%)$ kemudian responden yang umur 13 tahun $(33,3 \%)$ serta umur 15 tahun $(14,6 \%)$.

3. Distribusi responden berdasarkan golongan umur siswa kelas VIII SMP Negeri 1 Sangkub Kabupaten Bolaang Mongondow Utara dapat dilihat pada Tabel 3 di bawah ini:

Tabel 3. Distribusi Responden Berdasarkan Golongan Umur

\begin{tabular}{ccc}
\hline $\begin{array}{c}\text { Umur } \\
\text { (Tahun) }\end{array}$ & $\begin{array}{c}\text { Jumlah } \\
\text { Siswa }\end{array}$ & $\begin{array}{c}\text { Persentase } \\
(\%)\end{array}$ \\
\hline 13 & 16 & 33,3 \\
14 & 25 & 52,1 \\
15 & 7 & 14,6 \\
\hline Total & 48 & 100 \\
\hline
\end{tabular}

Data pada Tabel 3, menunjukkan bahwa jumlah responden yang paling banyak terdapat pada umur 14 tahun $(52,1 \%)$ kemudian responden yang umur 13 tahun $(33,3 \%)$ serta umur 15 tahun $(14,6 \%)$.

4. Distribusi responden berdasarkan kriteria OHIS sebelum promosi kesehatan menggunakan media leaflet dapat dilihat pada Tabel 4 berikut ini : 
JIGIM (Jurnal Ilmiah Gigi \& Mulut)

Tabel 4. Distribusi Responden

Berdasarkan Kriteria OHIS Sebelum

Promosi Kesehatan Menggunakan Media Leaflet

\begin{tabular}{ccc}
\hline $\begin{array}{c}\text { Kriteria } \\
\text { OHIS }\end{array}$ & Jumlah & $\begin{array}{c}\text { Persentase } \\
(\%)\end{array}$ \\
\hline Baik & 1 & 2,1 \\
Sedang & 35 & 72,9 \\
Buruk & 12 & 25 \\
\hline Total & 48 & 100 \\
\hline
\end{tabular}

Data pada Tabel 4 menunjukkan bahwa sebelum diberikan promosi kesehatan kriteria OHIS responden yang terbanyak yaitu kriteria sedang 35 responden (72,9\%), buruk 12 responden $(25 \%)$ dan kriteria baik 1 responden $(2,1 \%)$.

5. Distribusi responden berdasarkan kriteria OHIS sesudah promosi kesehatan menggunakan media Leaflet dapat dilihat pada Tabel 5 di bawah ini:

Tabel 5. Distribusi Responden

Berdasarkan Kritria OHIS Sesudah

Promosi Kesehatan Menggunakan Media

\begin{tabular}{ccc}
\multicolumn{3}{c}{ Leaflet } \\
\hline $\begin{array}{c}\text { Kriteria } \\
\text { OHIS }\end{array}$ & Jumlah & $\begin{array}{c}\text { Persentase } \\
(\%)\end{array}$ \\
\hline Baik & 33 & 68,8 \\
$($ Good $)$ & & 31,2 \\
$\begin{array}{c}\text { Sedang } \\
(\text { Fair })\end{array}$ & 15 & 0 \\
$\begin{array}{c}\text { Buruk } \\
(\text { Poor })\end{array}$ & 0 & 100 \\
\hline Total & 48 & \\
\hline
\end{tabular}

Data pada Tabel 5 menunjukkan bahawa Kriteria OHIS yang baik paling banyak 33 responden $(68,8 \%)$ dibandingkan kriteria sedang yaitu 15 responden $(31,2 \%)$. Untuk kriteria buruk sudah tidak ada responden $(0 \%)$.
Maramis JL, Promosi Kesehatan

6. Distribusi responden berdasarkan kriteria OHIS sebelum dan sesudah diberikan promosi kesehatan menggunakan media leaflet dapat dilihat pada Tabel 6 di bawah ini:

Tabel 6. Distribusi Responden

Berdasarkan Kriteria OHIS Sebelum dan

Sesudah Promosi Kesehatan Menggunakan Media Leaflet

\begin{tabular}{ccccc}
\hline $\begin{array}{c}\text { Kriteria } \\
\text { OHIS }\end{array}$ & Sebelum & $\%$ & Sesudah & $\%$ \\
\hline $\begin{array}{c}\text { Baik } \\
\text { (Good) }\end{array}$ & 1 & 2,1 & 33 & 68,8 \\
$\begin{array}{c}\text { Sedang } \\
(\text { Fair })\end{array}$ & 35 & 72,9 & 15 & 31,2 \\
$\begin{array}{c}\text { Buruk } \\
(\text { Poor })\end{array}$ & 12 & 25 & 0 & 0 \\
\hline Total & 48 & 100 & 48 & 100 \\
\hline
\end{tabular}

Data pada Tabel 6 menunjukkan bahwa kriteria OHIS sebelum promosi kesehatan menggunakan media leaflet sedang 35 responden $(72,9 \%)$, buruk 12 responden (25\%) dan baik 1 responden $(2,1 \%)$. Sedangkan sesudah diberikan promosi kesehatan menggunakan media leaflet Kriteria OHIS baik menjadi 33 responden $(68,8 \%)$, sedang 15 responden $(31,2 \%)$ dan buruk sudah tidak ada responden $(0 \%)$.

\section{Analisi Data}

Hasil uji statistik dengan menggunakan uji Paired Sample t dapat dilihat pada Tabel 7 di bawaht ini:

Tabel 7. Hasil Uji Mengenai Perbedaan

OHIS Sebelum Dan Sesudah Promosi

Kesehatan Menggunakan Media Leaflet

\begin{tabular}{ccccccc}
\hline Sblm & Ssdh & Mean & t hitung & df & $\alpha$ & $p$ \\
\hline 2.52 & 1.35 & 1.171 & 14.575 & 47 & 0.05 & 0.000 \\
\hline
\end{tabular}


Berdasarkan pada Tabel 7 menunjukkan bahwa nilai OHIS sebelum promosi kesehatan menggunakan media leaflet sebesar 2.52, sedangkan nilai OHIS sesudah promosi kesehatan menggunakan media leaflet sebesar 1.35. Berdasarkan hasil uji Paired Sample $t$ Test nilai OHIS sebelum dan sesudah promosi kesehatan menggunakan media leaflet mengalami penurunan yang signifikan yaitu nilai $p=$ $0.000(p<0.05)$.

\section{PEMBAHASAN}

Kebersihan gigi dan mulut adalah bersihnya rongga mulut, gigi dan lidah, serta bebasnya gigi dan mulut dari semua kotoran atau sisa-sisa makanan. ${ }^{3}$ Jika kebersihan gigi dan mulut diabaikan maka dapat menimbulkan dampak seperti karies gigi, bau mulut dan karang gigi. Salah satu cara agar dapat menjaga kebersihan gigi dan mulut, yaitu dengan promosi kesehatan menggunakan media leaflet. Banyak media yang digunakan dalam promosi kesehatan salah satunya media leaflet. Leaflet adalah media pembelajaran dalam bentuk selembar kertas yang dilipatlipat, berisi tulisan cetak dan beberapa gambar tertentu tentang suatu topik khusus untuk sasaran dan tujuan tertentu. Leaflet ini juga mempunyai kelebihan, yaitu dapat disimpan lama, sasaran dapat belajar mandiri, dan jangkauan pesan lebih luas, dengan demikian siswa mudah untuk mencerna materi yang diberikan dan diharapkan terjadi perubahan kebersihan gigi dan mulut dalam hal ini yaitu nilai OHIS pada siswa.

Penelitian yang dilakukan di SMP Negeri 1 Sangkub Kabupaten Bolaang Mongondow Utara dengan jumlah responden sebanyak 48 orang siswa, dimana kriteria kebersihan gigi dan mulut sebelum diberikan promosi kesehatan menggunakan media leaflet yang terbanyak ada pada kriteria sedang yaitu sebanyak 35 responden $(72,9 \%)$, kemudian kriteria buruk 12 responden $(25 \%)$ dan kriteria baik 1 responden $(2,1 \%)$. Hal ini menunjukkan bahwa responden belum mengetahui bagaimana pentingnya menjaga kebersihan gigi dan mulut dengan baik.

Hasil penelitian sesudah diberikan leaflet pada responden, dimana didapat nilai rata-rata OHIS pada kriteria baik mengalami peningkatan menjadi 33 responden $(68,8 \%)$, kriteria sedang 15 responden $(31,2 \%)$ dan kriteria buruk tidak ada responden. Hal ini disebabkan karena setelah diberikan promosi kesehatan menggunakan media leaflet tentang cara memelihara kesehatan gigi dan mulut yakni tentang tekhnik menyikat gigi yang baik dan benar, waktu menyikat gigi, rajin mengonsumsi buah-buahan yang dapat membersihkan gigi dan rutin kontrol ke puskesmas atau dokter gigi setiap 6 bulan sekali, terjadi perubahan perilaku siswa dimana siswa telah menerapkan ilmu yang didapat pada kehidupan sehari-hari, terbukti dengan menurunnya kriteria nilai OHIS pada siswa. Hal ini terjadi karena media leaflet mudah dilipat-lipat, berisikan tulisan cetak atau pesan-pesan dan juga beberapa gambar tertentu.

Hal ini sejalan dengan penelitian yang dilakukan oleh Nubatonis (2017) tentang "Promosi Kesehatan Gigi Dengan Menggunakan Media Leaflet Terhadap Pengetahuan, Sikap, dan Status Kebersihan Gigi dan Mulut Siswa Sekolah Dasar Kota Kupang" yang menyatakan bahwa promosi kesehatan gigi dan mulut dengan menggunakan media leaflet dapat meningkatkan secara bermakana pengetahuan, sikap dan kebersihan gigi 
dan mulut siswa Sekolah Dasar. Peningkatan pengetahuan seseorang dapat dilakukan dengan cara menyebarkan pesan, menanamkan keyakinan sehingga masyarakat tidak saja sadar, tahu dan mengerti, tetapi juga mau dan bisa melakukan suatu anjuran yang ada hubungannya dengan kesehatan khususnya kesehatan gigi dan mulut. ${ }^{8}$

Berdasarkan uji statistik tentang efektivitas promosi kesehatan menggunakan media leaflet terhadap kebersihan gigi dan mulut pada responden dengan tingkat kemaknaan $95 \%(\alpha=$ $0,05)$ diperoleh nilai signifikan $p=0.000$ (nilai $p<0,05)$. Hasil ini menyatakan bahwa adanya perbedaan yang signifikan antara nilai OHIS sebelum dan sesudah pemberian leaflet pada responden. Dengan demikian, maka Ho ditolak dan $\mathrm{H} 1$ diterima, ini berarti bahwa promosi kesehatan gigi dan mulut dengan menggunakan leaflet sangat membantu dalam meningkatkan pengetahuan responden, sehingga upaya untuk merubah perilaku seseorang atau kelompok masyarakat dalam menjaga kebersihan gigi dan mulut dapat terlaksana dengan baik.

Hasil penelitian sejalan dengan penelitian yang dilakukan oleh Hermawan, dkk (2015), yang menyatakan bahwa terdapat perbedaan yang bermakna antara debris indeks sebelum dan sesudah dilakukan promosi kesehatan dengan leaflet tentang menyikat gigi pada murid SD Negeri Poigar. ${ }^{9}$

\section{KESIMPULAN}

Berdasarkan hasil penelitian yang dilakukan, maka dapat dismpulkan bahwa sebelum diberikan promosi kesehatan menggunakan media leaflet didapatkan kriteria OHIS yang paling banyak yaitu kriteria sedang dan sesudah diberi perlakuan kriteria OHIS menjadi baik, dimana pada penelitian ini menggunakan tingkat kemaknaan $95 \%(\alpha=0.05)$ dan diperoleh nilai $p=0.000(p<0.05)$.

\section{SARAN}

1. Bagi Siswa, hendaknya dapat menjaga kebersihan gigi dan mulut secara teratur dengan menyikat gigi minimal $2 \mathrm{x}$ sehari dengan waktu yang tepat yaitu pagi sesudah sarapan dan malan sebelum tidur, mengurangi makanan yang manis dan mudah melekat serta rajin memeriksakan kesehatan gigi dan mulut ke puskesmas atau dokter gigi setiap 6 bulan sekali

2. Bagi sekolah, dapat menggunakan media leaflet sebagai media perantara dalam proses belajar mengajar serta dapat meningkatkan kerjasama dengan puskesmas yang ada diwilayah setempat untuk memberikan promosi kesehatan gigi lewat kegiatan UKGS yang ada dalam hal meningkatkan derajat kesehatan gigi dan mulut.

\section{DAFTAR PUSTAKA}

1. Kemenkes RI. (2012). Pedoman Usahan Kesehatan Gigi Sekolah di SMP dan SMA atau yang Sederajat. Jakarta

2. Putri, M.H. 2011.Ilmu Pencegahan Penyakit Keras dan Jaringan Pendukung Gigi.EGC. Jakarta

3. Isro'in, L, \& Andarmoyo, S. (2012). Personal Hygiene. GRAHA ILMU. Yogyakarta 
4. Kemenkes RI. (2011). Promosi Kesehatan di Daerah Bermasalah Kesehatan . Jakarta

5. Suiraoka I,P., dan Supariasa I,D,N. (2012). Media Pendidikan Kesehatan. Graha Ilmu. Yogyakarta.

6. Susilana, R dan Riyana, C. (2007). Media Pembelajaran. CV Wacana Prima. Bandung

7. Notoatmodjo, S. (2010). Promosi Kesehatan Teori \& Aplikasi. Rineka Cipta. Jakarta

8. Nubatonis M.O., (2017). Promosi Kesehatan Gigi Dengan Menggunakan Media Leaflet Terhadap Pengetahuan, Sikap Dan Status Kebersihan Gigi Dan Mulut Siswa Sekolah Dasar Kota Kupang. Poltekkes Kemenkes Kupang Jurusan Keperawatan Gigi.

9. Hermawan., Umboh. A, Mintjelungan, C. (2015). Indeks Debris Sebelum Dan Sesudah Dilakukan Promosi Kesehatan Tentang Menyikat Gigi Pada Murid Sd Negeri Poigar. Jurnal e-GIGI (eG). https://ejournal.unsrat.ac.id/index.php (diakses pada 3 Mei 2019 